Pesq. Vet. Bras. 30(8):689-695, agosto 2010

\title{
Estudo morfofuncional das glândulas mamárias de Mão Pelada, Procyon cancrivorus ${ }^{1}$
}

\begin{abstract}
Tatiana Bellatine ${ }^{2}$, Celina A.F. Mançanares ${ }^{2,3}$, André Luis R. Franciolli ${ }^{3}$, Carlos E. Ambrósio ${ }^{2,3}$, Daniele S. Martins ${ }^{3}$, Maria Angélica Miglino ${ }^{3}$ e Ana Flávia Carvalho ${ }^{2 *}$

ABSTRACT.- Bellatine T., Mançanares C.A.F., Franciolli A.L.R., Ambrósio C.E., Martins D.S., Miglino M.A. \& Carvalho A.F. 2010. [Morphofunctional study of Crab-eating Raccoon (Procyon cancrivorus) mammary gland.] Estudo morfofuncional das glândulas mamárias de Mão Pelada, Procyon cancrivorus. Pesquisa Veterinária Brasileira 30(8):689-695. Departamento de Morfologia, Faculdade de Medicina Veterinária, Centro Universitário da Fundação de Ensino Octávio Bastos, Avenida Octávio Bastos s/n, Jardim Nova São João, São João da Boa Vista, SP 13870-000, Brazil. E-mail: labvet01 @unifeob.edu.br

Three Procyon cancrivorus females were studied with emphasis for gross and microscopical description of the mammary glands. Samples of the glands were processed with routine techniques for histology. The females studied presented three pairs of mammary glands: one pair of cranial abdominal mammary glands, a second pair of caudal abdominal and a third one, as inguinal mammary glands. Mammary papillae presented a pendulum shape, as in the domestic dogs. Microscopically, the mammary gland consisted from the external to the internal portion (1) of stratified squamous epithelium of the epidermis, (2) dense irregular connective tissue of the derma, and (3) smooth muscle fibers and papillary ducts that flowed with "shower" shape into the lactiferous sinus. The secretory portion consisted of tubule-alveolar glands with cuboidal cells disposed in a simple layer. The results indicate that the set of glandular studies is similar to ones related to dog (Canis familiaris) in such a way in its gross aspect that how much in its microscopically structure. This fact suggests that we can use the raccoon and the dog as similar models of study, for identification of pathologies related to this system.
\end{abstract}

INDEX TERMS: Procyon cancrivorus, raccoon, mammary gland, morphology.

RESUMO.- Para a descrição macro e microscópica das glândulas mamárias foram utilizadas três fêmeas de Mão Pelada (Procyon cancrivorus). As amostras das glândulas foram processadas conforme técnicas rotineiras para histologia. As fêmeas estudadas apresentaram 3 pares de glândulas mamárias, sendo um par de glândula mamária abdominal cranial, um par de abdominal caudal e um par de inguinal. As papilas mamárias apresentaram formato

\footnotetext{
${ }^{1}$ Recebido em 26 de março de 2010.

Aceito para publicação em 8 de abril 2010.

${ }^{2}$ Centro Universitário da Fundação de Ensino Octávio Bastos, Av. Octávio Bastos s/n, Jd. Nova São João, São João da Boa Vista. SP 13870-000, Brasil. *Autor para correspondência: labvet01 @ unifeob.edu.br

${ }^{3}$ Departamento de Cirurgia, Faculdade de Medicina Veterinária e Zootecnia, Universidade de São Paulo (USP), Av. Prof. Orlando Marques de Paiva 87, Cidade Universitária, São Paulo, SP 05508-270, Brasil.
}

pendular, como os canídeos domésticos. Microscopicamente, a glândula mamária apresentou da porção externa para a interna: epiderme (epitélio estratificado pavimentoso queratinizado), derme (tecido conjuntivo frouxo e tecido conjuntivo denso não modelado), fibras musculares lisas e ductos papilíferos que abrem em vários ósteos papilares em formato de "chuveiro". A porção secretora glandular era caracteristicamente túbulo alveolar, com células cuboidais dispostas em camada simples. Os resultados indicam que o conjunto glandular estudado é semelhante ao da cadela (Cannis familiaris) tanto em seu aspecto macroscópico quanto em seu aspecto microscópico, este fato sugere que podemos utilizar o Mão Pelada e o Cão como modelos similares de estudo, para identificação de patologias relacionadas a este sistema.

TERMOS INDEXADOS: Procyon cancrivorus, guaxinim, mãopelada, glândula mamária, morfologia. 


\section{INTRODUÇÃO}

O Procyon cancrivorus, guaxinim, "mão-pelada" ou raccoon, como é conhecido nos Estados Unidos, pode medir $60 \mathrm{~cm}$ de comprimento e mais $40 \mathrm{~cm}$ de cauda e pesar até $20 \mathrm{~kg}$. Estes animais, que hibernam nos países de clima frio, com ninhadas de 4-6 filhotes, têm sido estudados principalmente no que tange à disseminação de doenças pelos animais silvestres (Machida et al. 1993). Alguns autores brasileiros Casals et al. (2005) descreveram morfologicamente a glândula mamária de quatis e Favaron et al. (2008) a glândula pineal de quatis, um animal da mesma família do Mão Pelada.

Gurtler et al. (1987) averiguaram, nas fêmeas que, as glândulas mamárias crescem durante o desenvolvimento fetal, formando um sistema de ductos rodeado por tecido conjuntivo e adiposo. Após o nascimento a massa das glândulas mamárias continua aumentando. Cada complexo da glândula mamária possui um corpo glandular funcional e uma papila mamária, onde desemboca um sistema excretor.

Ellenport (1981) afirmou que os carnívoros domésticos, de forma geral, têm normalmente as glândulas mamárias em número de 10, isto é, 5 pares de glândulas, as quais estão dispostas em 2 séries estendendo-se da parte caudal da região peitoral até a região inguinal; são, portanto, designadas de acordo com a localização, como 4 torácicas; 2 torácicas craniais e 2 torácicas caudais, 4 abdominais; 2 abdominais craniais e 2 abdominais caudais e 2 inguinais.

De acordo com Dyce et al. (1997) na cadela os dois pares craniais são torácicos, os dois seguintes são abdominais e o último par está em posição inguinal. Seu padrão é freqüentemente alternado, num arranjo favorável, para proporcionar que todas as papilas mamárias sejam igualmente acessíveis aos filhotes quando em decúbito lateral. São recobertas por pêlos, que podem esconder completamente as papilas mamárias, apesar destas permanecerem aumentadas em cadelas paridas, nas quais se superpõem aos órgãos abdominais em radiografias ventrodorsais. As glândulas tornam-se mais salientes próximo ao parto e durante a lactação ficando intumescidas, pendulosas e confluentes com as vizinhas ipsolaterais. O suprimento sangüíneo das glândulas mamárias varia, mas freqüentemente origina-se das artérias torácicas internas e laterais e da pudenda externa, alguma contribuição pode ser conferida por vasos menores de outras origens. Na maioria dos casos, as três glândulas craniais são supridas craniolateralmente pela artéria torácica lateral e profundamente pela artéria epigástrica superficial cranial e pelos ramos perfurantes das artérias intercostais. Os dois pares caudais são supridos pela artéria epigástrica superficial caudal e profundamente pelos ramos das artérias abdominal cranial e ilíaca circunflexa profunda sendo que as veias são satélites. Tanto as artérias como as veias anastomosam-se livremente, formando plexos arteriais e venosos.

Park \& Jacobson (1993) descreveram que as glândulas mamárias assemelham-se as glândulas sebáceas e sudoríparas cutâneas. Histologicamente, nos mamíferos ela é do tipo tubuloalveolar composta e se origina do ectoderma. Embora a glândula mamária seja basicamente semelhante em todos os mamíferos, há amplas variações entre espécies quanto ao aspecto da glândula e quantidades relativas dos componentes secretados.

Banks (1992) e Gaona et al. (1999) também ao descreverem as glândulas mamárias, afirmaram ser um órgão formado por glândulas tubuloalveolares compostas, sendo considerada uma glândula sudorípara modificada. Os lipídios da glândula são secretados pelo método apócrino, enquanto as proteínas e os carboidratos são secretados pelo método merócrino. As glândulas em lactação têm muito parênquima e pouco tecido conjuntivo, enquanto o inverso é verdadeiro para as glândulas que não estão em lactação.

Banks (1992) relatou ainda que o seio das tetas e do tecido glandular nem sempre estão separados pelo ânulo, eles são chamados coletivamente de seio lactífero. O seio da teta se continua com a pele através do canal da teta (ducto papilar). O orifício interno deste canal é marcado pela transição abrupta para epitélio pavimentoso estratificado (queratinizado). O tecido conjuntivo da glândula varia conforme a sua posição no órgão. O tecido conjuntivo frouxo, esparso, e o reticular, intralobular, são muito vascularizados. O tecido conjuntivo interlobular (intralobar) e o interlobar são frouxos. Feixes de fibras musculares lisas e de fibras elásticas estão presentes em volta dos grandes ductos.

A glândula mamária é uma estrutura que apresenta respostas variáveis aos hormônios esteróides. Sua interação hormonal é complexa, envolvendo os esteróides sexuais, os quais atuam por via autócrina, parácrina e endócrina. $O$ estradiol possui importante papel no desenvolvimento das células ductais e do estroma. A progesterona, em sinergismo com o estradiol e a prolactina, promove o desenvolvimento e diferenciação acinar. As alterações dos hormônios esteróides podem determinar importantes distúrbios mamários como: dor, nodulações e neoplasias, tanto benignas quanto malignas (Shida et al. 2001).

D'Arce \& Flechtman (1979) afirmaram que o equilíbrio entre os hormônios, mantidos durante a gestação, completa o desenvolvimento da glândula, mas, inibe a lactogênese. A prolactina, elaborada na hipófise, determina, nas proximidades do parto, o funcionamento da glândula que, inicialmente, produz colostro, depois, leite. O colostro encerra, entre outros componentes, anticorpos às doenças as quais a mãe foi exposta, sendo de grande importância para o recém-nascido.

Depois de apurada busca na literatura e tendo observado o escasso número de trabalhos publicados, objetivouse com o presente artigo estudar as características morfológicas, da glândula mamária, por quanto sua inquestionável importância se reporta não só no desenvolvimento dos fiIhotes como também na perpetuação da espécie.

\section{MATERIAL E MÉTODOS}

Para a avaliação macroscópica e microscópica da glândula mamária de Procyon cancrivorus, foram utilizados três fêmeas de Mão Pelada, sem idade definidas, adultas, ortotanasiados com thelazol@ $0,20 \mathrm{mg} / \mathrm{kg}$ e posterior injeção de cloreto de potássio IV $-10 \mathrm{ml}$, segundo as normas do Comitê de Bioética e 
Experimentação Animal (COBEA), provenientes do Criatório Científico do Centro de Criação, Multiplicação e Pesquisa em Animais Silvestres (Cecrimpas), Centro Universitário da Fundação de Ensino Octávio Bastos (Unifeob), autorizado pelo IBAMA, Proc.02027.00286/04-92.

Após a ortotanásia dos animais, a aorta abdominal e a veia jugular foram canuladas do lado esquerdo e procedeu-se à injeção com látex Neoperene $650^{\circledR}$ sendo, respectivamente, vermelho para a artéria e azul para a veia até repleção de todos os vasos. Em seguida os animais foram fixados em solução de formaldeído a $10 \%$, mantendo as respectivas posições das glândulas mamárias in situ e, para seguir serem dissecadas e fotografadas.

Foram coletados fragmentos das glândulas mamárias, da base até o ápice glandular ao redor de toda a circunferência (longitudinal e transversal) que foram desidratados em concentrações crescentes de etanol (70-100\%), diafanizados em xilol e embebidos em histosec® (Merck, Lote K91225309), seguindo as técnicas rotineiras para inclusão (Tolosa et al. 2003). Os blocos foram cortados em micrótomo Leica RM 2165, com espessura média de $5 \mu \mathrm{m}$ e corados por hematoxilina-eosina (Tolosa et al. 2003), picrosírius (Junqueira et al. 1979), reação histoquímica de PAS (Ácido periódico de Schiff), com fundo de hematoxilina (Lillie \& Fulmer 1976) e tricrômio de Masson (Tolosa et al. 2003). O material foi analisado e fotografado através de um fotomicroscópio Eclipse Nikon E-400.

\section{RESULTADOS E DISCUSSÃO}

Foi observada a presença de 3 pares de glândulas mamárias, sendo 1 par de glândulas mamárias abdominais craniais, 1 par de glândulas mamárias abdominais caudais e 1 par de glândulas mamárias inguinais. Segundo Casals et al. (2005) para o Nasua nasua, outra espécime da Família Procyonidae, a mesma disposição das glândulas mamárias foi observada (Fig.1). Neste estudo, porém, puderamse averiguar diferenças quanto à disposição dos pares de glândulas mamárias para os carnívoros domésticos (cão) descritas por Ellenport (1981) cujo trabalho relata que os carnívoros domésticos, de forma geral, têm normalmente as glândulas mamárias em número de 10, isto é, 5 pares

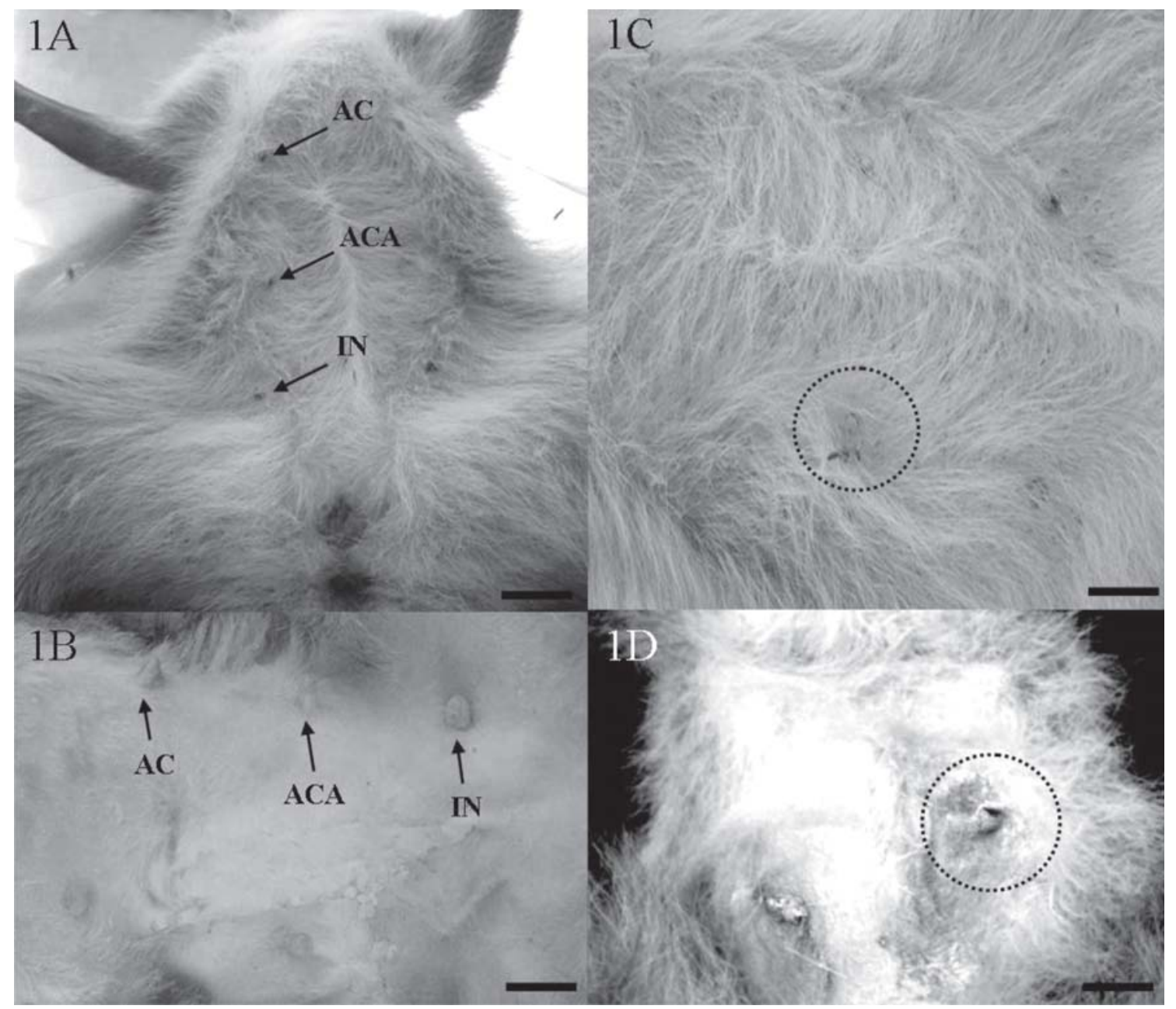

Fig.1. Glândula mamária de Procyon cancrivorus. (A) Os 3 pares de glândulas mamárias, divididas em AC, abdominal cranial; ACA, abdominal caudal e IN, inguinal. (B) Disposição das glândulas mamárias de Nasua nasua (cedido por Casals 2005) semelhantes às de Procyon cancrivorus. (C) Região da cadeia mamária com uma área rica em pêlos e ausência de pigmentação (círculo). (D) Presença de pigmentação nas papilas mamárias (círculo). Barra: $3 \mathrm{~cm}$. 


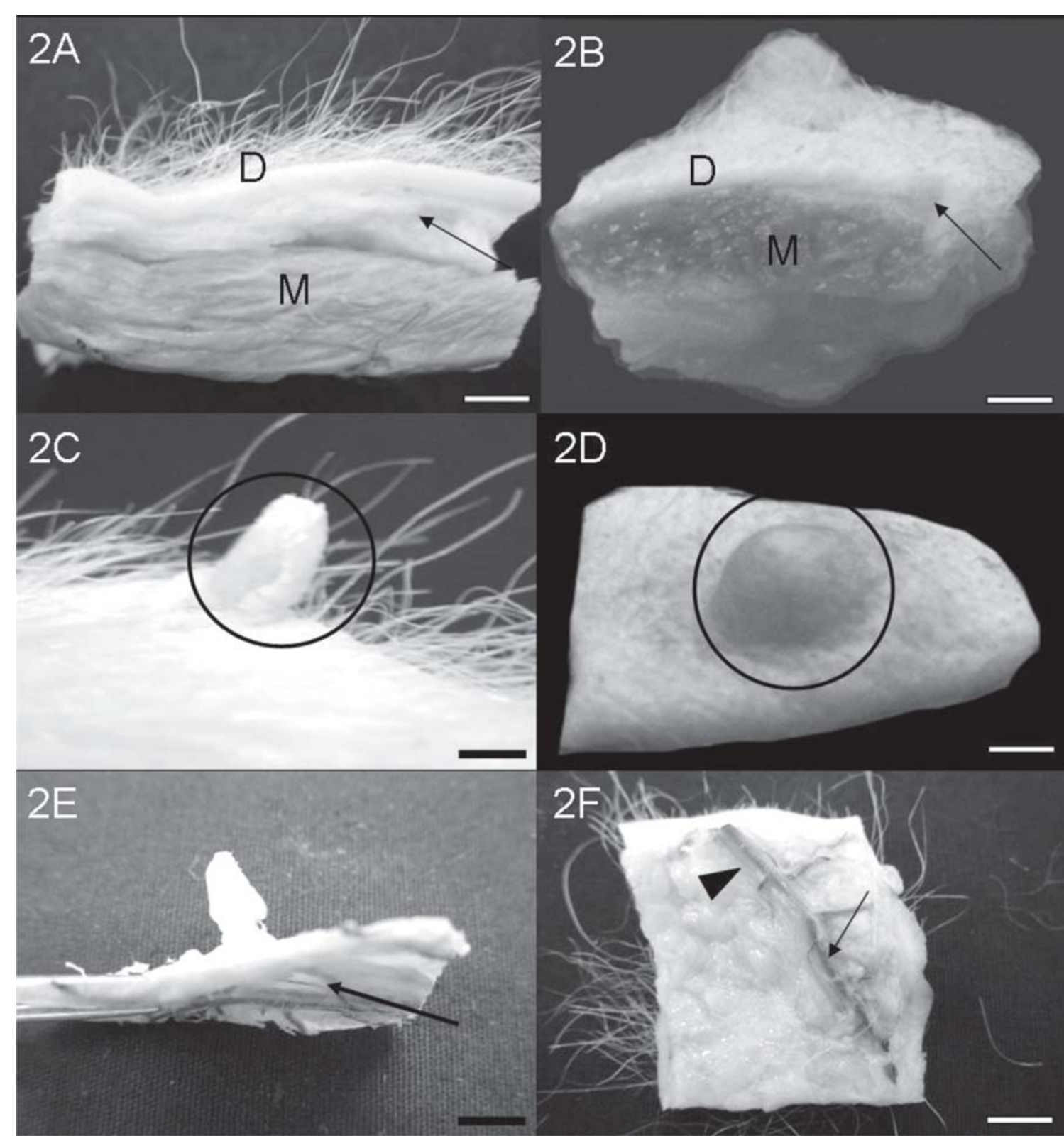

Fig.2. Região mamária seccionada transversalmente de Procyon cancrivorus e de Nasua nasua. (A,B) Camada espessa de tecido adiposo (seta) de Procyon cancrivorus diferente do Nasua nasua, separando a derme (D) e do músculo reto do abdome (M). (C,D) Nota-se as diferenças das papilas mamárias da fêmea de Procyon cancrivorus e a da fêmea de Nasua nasua (círculo) (cedido por Casals et al. 2005) . (E) Após dissecção da epiderme da papila, o tecido glandular logo abaixo da papila está afuncional (seta), de Procyon cancrivorus. (F) Os ramos arteriais da artéria epigástrica superficial caudal (seta) e os ramos venosos da veia epigástrica superficial caudal (cabeça de seta) de Procyon cancrivorus. Barra: $1 \mathrm{~cm}$.

de glândulas, as quais estão dispostas em 2 séries estendendo-se da parte caudal da região peitoral até a região inguinal; são, portanto, designadas de acordo com a localização, como 4 torácicas; 2 torácicas craniais e 2 torácicas caudais, 4 abdominais; 2 abdominais craniais e 2 abdominais caudais e 2 inguinais.

Dyce et al. (1997) afirmaram que em diferentes espécies, as glândulas são recobertas por pêlos que escondem completamente as papilas mamárias. Nesta espécie sil- vestre, objetivo deste trabalho, observou-se que cadeia mamária era abundante em pêlos incluindo a papila As papilas mamárias mostravam-se despigmentadas em dois animais, enquanto, um outro animal Mão Pelada apresentou esta região pigmentada e com pouco pêlo em relação aos outros animais (Fig.1).

A cadeia mamária apresentou uma espessa camada de tecido adiposo (Fig.2), que separava o músculo reto do abdome da derme, ao contrário do observado em Nasua 
nasua, segundo Casals et al. (2005) mesmo os animais em estado nutricional adequado.

Em nossos resultados, as papilas mamárias apresentaram formato arredondado e pendular, revelando semeIhanças às do cão doméstico observado por Dyce et al. (1997), todavia, quando comparadas com a glândula mamárias de Nasua nasua descrito por Casals et al. (2005) apresentaram-se diferentes exibindo as papilas cônicas características. Os animais utilizados no presente trabaIho encontravam-se fora do período de lactação. A glândula mamária, portanto encontrava-se afuncional, de tamanho pequeno e sem características secretórias (Fig.2).

Após a injeção de látex e sua dissecação foi analisada a irrigação da glândula mamária de Mão Pelada (Procyon cancrivorus), notando-se a cadeia mamária constituída pela artéria epigástrica superficial cranial e a veia epigástrica superficial cranial que desembocam na veia cava cranial e pela veia e artéria epigástrica superficial caudal, um ramo da pudenda, sendo drenada pela veia e artéria epigástrica superficial caudal. O presente resultado difere dos relatos de Dyce et al. (1997) referente a carnívoros (cão) sendo esta última mais complexa, composta por ramos craniais que vascularizam um maior número de glândulas mamárias (Fig.2).

Histologicamente observou-se que a papila mamária é revestida externamente pelo epitélio pavimentoso estratificado queratinizado e na derme papilar era constituída, respectivamente por tecido conjuntivo frouxo e denso não mo-

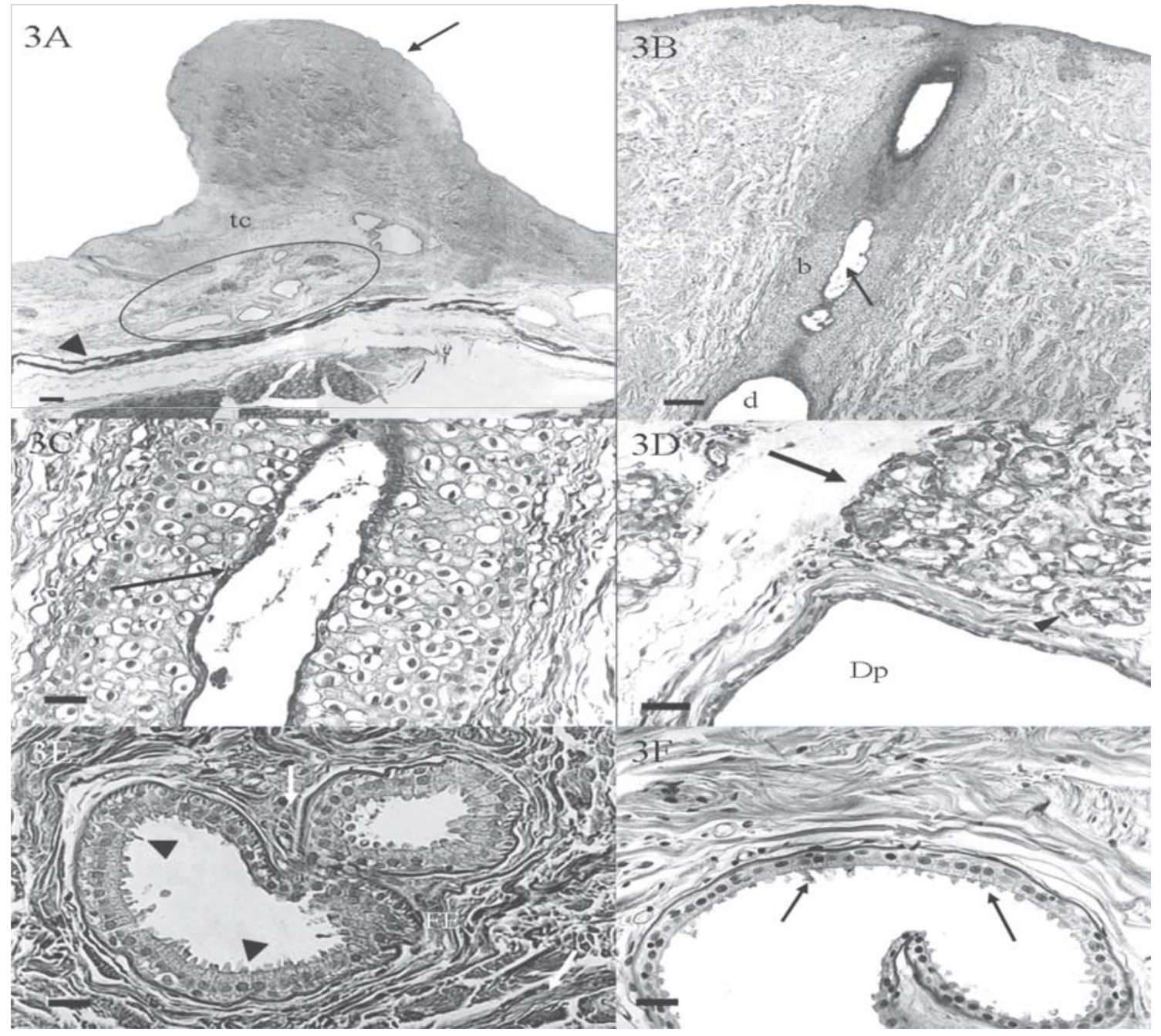

Fig.3. Glândulas mamárias de Procyon cancrivorus. (A) Os estratos: epitélio (seta), tecido conjuntivo (tc), fibras musculares lisas (cabeça de seta) e parênquima glandular (círculo). HE, Barra: $200 \mathrm{~mm}$. (B) Ducto papilar (d) intimamente relacionado a um folículo piloso (seta) e sua bainha epitelial (b). HE, Barra:

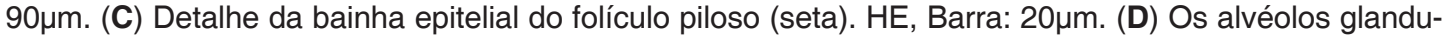
lares (seta) com atividade mitótica (cabeça de seta) ao lado do ducto papilar (Dp). HE, Barra: 20mm. (E) Grande quantidade de fibras colágenas (FE) ao redor dos ductos e a presença de fibras musculares lisas em diferentes arranjos, longitudinal e transversal (setas); notar também as células ductais com rara secreção (cabeça de setas). Tricrômio de Masson, Barra: $20 \mathrm{~mm}$. (F) A luz do ducto papilar cúbico simples, com rara secreção (setas). Reação histoquímica de PAS, Barra: $20 \mathrm{~mm}$. 

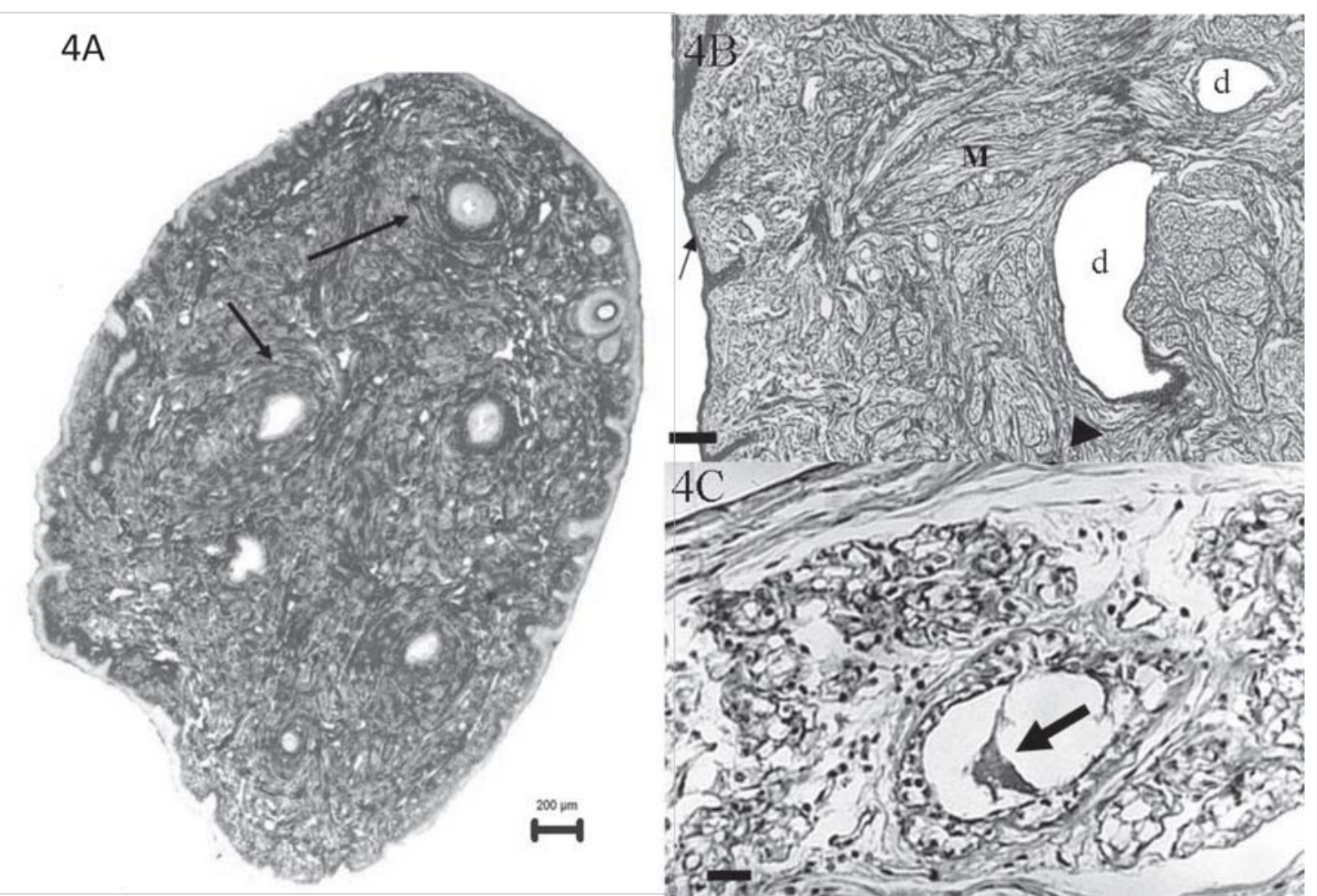

Fig.4. Glândula mamária de Procyon cancrivorus. (A) Arranjos de tecido conjuntivo ao redor das papilas

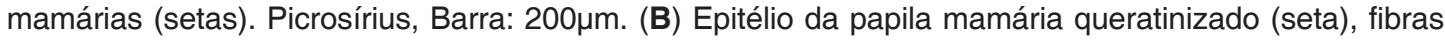
do tecido conjuntivo (cabeça de seta), ductos (d) e fibras musculares (M). Tricromo de Masson, Barra:

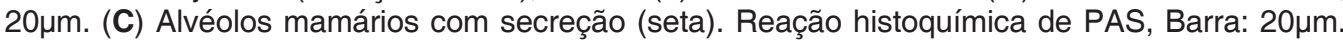

delado, entremeadas de fibras musculares à derme reticular. Estas fibras agrupam-se para formar as camadas circulares e longitudinais de músculo liso ao redor dos ductos papilares (Fig.3). Achados semelhantes em animais domésticos (cão) foram descritos por Banks (1992), bem como em marsupiais por Samoto et al. (2006). Os ductos papilares são em grande número (mais de seis) e abrem-se em vários ósteos papilares, assemelhando-se aos das cadelas quando em lactação. Este formato de excreção de leite foi idêntico nestes animais apresentando um aspecto de "chuveiro" (Banks 1992) e Bacha Jr \& Wood (1990) (Fig.3).

Abaixo da papila mamária, microscopicamente observou-se o tecido glandular túbulo alveolar entremeado por tecido conjuntivo frouxo (Fig.3) semelhante ao descrito por Banks (1992) e Gaona et al. (1999) para os animais domésticos.

Os alvéolos glandulares eram constituídos por células secretoras cúbicas com intensa atividade mitótica (Fig.3) estes se encontravam ao lado dos ductos papilares.

Cortes transversais da papila mamária mostraram uma grande quantidade de fibras colágenas e fibras musculares lisas evidenciadas pela coloração de tricrômio de Masson que se encontram ao redor dos ductos. No corte longitudinal da glândula mamária, revelaram um ducto papilar em processo de secreção, onde os núcleos estão em posição apical durante o processo de secreção como tem sido afirmado por Banks (1992). (Fig.3).
Nas papilas mamárias, observou-se uma grande quantidade de tecido conjuntivo, os quais foram encontrados os ductos papilares, como descritos por Gurtler et al (1987) para as espécies domésticas, além de fibras musculares dispersas no tecido conjuntivo, como descrito por Santos (2000). (Fig.4)

Externamente, as glândulas mamárias apresentaram glândulas sebáceas, as quais se encontravam inseridas no tecido conjuntivo rico em fibras musculares, cujas características também foram relatadas em espécies domésticas (cão) por Park \& Jacobson (1993) e em búfalas por Uppal et al. (1995) e Santos et al. (2007). (Fig.4)

No parênquima da glândula mamária evidenciou-se os alvéolos mamários apresentando epitélio com atividade secretora, cujo ápice continhagotículas características de exocitose. $\mathrm{O}$ epitélio cuboidal possuía células basais com intensa atividade mitótica, assemelhando-se àqueles descritos para as espécies domésticas (Fig.4) por Banks (1992) e Gaona et al. (1999).

\section{CONCLUSÕES}

Macroscopicamente pudemos concluir que, as glândulas mamárias e papilas mamárias de Mão Pelada (Procyon cancrivorus) diferem de cadela (Canis familiaris) quanto à quantidade de glândulas como também no formato.

Quando comparadas às glândulas mamárias de Quati (Nasua nasua), outro espécime da família Procyonidae, 
as glândulas assemelham-se na quantidade porém diferem no formato da papila mamária.

Microscopicamente não houve diferença na arquitetura dos tecidos, apresentando estruturas histológicas semeIhantes aos canídeos domésticos, bem como para Nasua nasua (quati).

Agradecimentos.- À Fundação de Amparo à Pesquisa do Estado de São Paulo (FAPESP) que nos permitiu o desenvolvimento deste trabalho através de projeto de Auxílio Pesquisa e Bolsa de Iniciação Científica.

\section{REFERÊNCIAS}

D’Arce R.D. \& Flechtmann C.H.W. 1979. Introdução à Anatomia e Fisiologia Animal. Nobel, São Paulo, p.186.

Bacha Jr W.J. \& Wood L.M. 1990. Color Atlas of Veterinary Histology. Lea and Febiger, Philadelphia, p.96-97.

Banks W.J. 1992. Histologia Veterinária Aplicada. $2^{\underline{a}}$ ed. Manole, São Paulo. 629p.

Casals J.B., Carvalho A.F., Ambrosio C.E., Mançanares C.A.F., Miglino M.A., Rosa R.A., De Lima M.G. \& Roqueto M.A. 2005. Morphology of Coati mammary gland, Nasua nasua. Braz. J. Morphol. Sci. 42(Suppl.):132.

Dyce K.M., Sack W.O. \& Wensing C.J.G. 1997. Tratado de Anatomia Veterinária. 2a ed. Guanabara Koogan, Rio de Janeiro, p.477-482.

Ellenport C.R. 1981. Aparelho urogenital do carnívoro, Cap.53. In: Sisson e Grossman's Anatomia dos Animais Domésticos. 5 $5^{\underline{a}}$ ed. Interamericana, Rio de Janeiro, p.2000.

Favaron P.O., Mançanares C.A.F., Ambrosio C.E., Leise R., Miglino M.A. 2008. Gross and Microscopic Anatomy of the Pineal Gland in Coati (Linnaeus, 1766). Anatomia, Histologia, Embryologia 37:464468.

Gaona H.V., Laville R.E., Arce S.R.A. \& Martínez M.P. 1999. Distribución de mastocitos del estroma de la glándula mamaria de perra (Canis familiaris), en periodos activo e inactivo. Vet. Méx. 30(4):317-321.

Gürtler H., Ketz H.A., Kolb E., Schröder L. \& Seidel H. 1987. Fisiologia Veterinária. $4^{\underline{a}}$ ed. Guanabara Koogan, Rio de Janeiro, p.612.

Junqueira L.C., Bignonas G. \& Bretan R.P. 1979. Picrosirius staining plus polarization microscopy, a specific method for collagen detection in the tissue sections. Histochem. J. 11:447-255.

Lillie R.D. \& Fulmer H.M. 1976. Histopathologic Technic and Practical Histochemistry. $4^{\text {th }}$ ed. McGraw Hill, New York, p.942.

Luiz C.R., Oliveira K.M., Balestra R.A.M., Nascimento D.S. \& Ferreira J.R. 2004. Estudo comparativo da irrigação da papila mamária em cães sem raça definida (Canis familiaris, Linnaeus, 1758). Braz. J. Vet. Res. Anim. Sci. 41(1):20-24.

Machida N., Kiryu K., Kanda E., Izumisawa N. \& Nakamura T. 1993. Pathology and epidemiology of canine distemper in raccoon dogs (Nyctereutes procyonoides). J. Comp. Pathol. 108(4):383-392.

Orr R.T. 1986. Biologia dos Vertebrados. $5^{\text {a }}$ ed. Roca, São Paulo, p.508.

Park C.S. \& Jacobson N.L. 1993. Glândula Mamária e lactação, Cap.37. In: Swenson M.J. \& Reece W.O. (Eds), Fisiologia dos Animais Domésticos. $11^{\underline{a}}$ ed. Guanabara Koogan, Rio de Janeiro, p.856.

Santos D.A.S., Vicente W.R.R., Canola J.C. \& Léga E. 2004. Estudo da papila mamária em fêmeas bovinas (Bos taurus Linnaeus, 1758), mediante as características ultra-sonográficas em modo-B (tempo rela). Braz. J. Vet. Res. Anim. Sci. 41(5):349-354.

Santos D.A.S., Ricci R.E.G., Prado I.M.M., Carvalho A.F., Bombonato P.P., Ambrósio C.E., Teixeira D.G., Santos T.C., Hernandes-Brazquez F.J., Martins D.S., Morini A.C., Kfoury Jr J.R. \& Miglino M.A. 2007. Morfologia e morfometria das papilas mamárias de búfalas. Pesq. Vet. Bras. 27(3):95-102.

Samoto V.Y., Miglino M.A., Ambrósio C.E., Pereira F.T.V., Lima M.C. \& Carvalho A.F. 2006. Morfologia da glândula mamária de gambás da espécie Didelphis sp associada ao modelo marsupial. Biota Neotrop. 6(2):1-12. DOI: 10.1590/S1676-06032006000200014.

Shida J.Y., Gebrim L.H., Simões M.J., Baracat E.C. \& De Lima G.R. 2001. Morphological and morphometrical study of permanent estrus rat mammary gland treated with Danazol. Revta Bras. Ginecol. Obstetr. 23(1):41-45.

Tolosa E.M.C., Rodrigues C.J., Behmer O.A. \& Freitas-Neto A.G. 2003. Manual de Técnicas para Histologia Normal e Patológica. $2^{\underline{a}}$ ed. Manole, São Paulo, p.331.

Uppal S.K., Singh K.B., Bansal B.K., Nauriyal D.C. \& Roy K.S. 1995. Histomorphological study on the teat (Mammary papilla) of Indian buffalo. Indian J. Anim. Sci. 65:853-856. 